\title{
ELEIÇÕES E REDES SOCIAIS: UMA ANÁLISE DAS POSTAGENS DA CANDIDATA MANUELA D'ÁVILA NO FACEBOOK
}

\author{
Gabrielle dos Santos Marques ${ }^{1}$
}

\begin{abstract}
Resumo
Inspirado em pesquisas que buscam compreender a mobilização de uma ideia de feminino nas campanhas eleitorais de candidatas mulheres, o objetivo central deste trabalho é analisar como a candidata à vice-presidência no último pleito eleitoral (2018) Manuela D'Ávila (PT/PCdoB/PROS) utiliza de estereótipos de gênero como estratégia de campanha eleitoral no Facebook, além de outras estratégias. A metodologia utilizada foi a análise de conteúdo e os dados foram coletados através do aplicativo Netvizz, um programa que permite a mineração das postagens na plataforma. As considerações finais apontam como o uso da página do Facebook de Manuela ilumina novas possibilidades de campanhas eleitorais femininas. Sem abrir mão de destacar sua maternidade, e o óbvio fato de que é uma mulher, Manuela, quando fala sobre questões relacionadas ao universo feminino, não o faz de forma essencializada, demonstrando uma visão crítica, sobre temas delicados como representatividade, mercado de trabalho e violência.
\end{abstract}

Palavras-chave: campanha eleitoral; redes sociais; essencialização; Manuela D'Ávila; Facebook

\section{Elections and social networks: an analysis of the posts of candidate Manuela} D'Ávila on Facebook

\begin{abstract}
Inspired by research that seeks to understand the mobilization of an idea of women in the election campaigns of women candidates, the main objective of this paper is to analyze how the candidate for the vice presidency in the last election (2018) Manuela D'Ávila (PT / PCdoB / PROS) uses gender stereotypes as an electoral campaign strategy on Facebook, in addition to other strategies. The methodology used was content analysis and data were collected through the Netvizz application, a program that allows the mining of posts on the platform. Final considerations point out how the use of Manuela's Facebook page illuminates new possibilities for women's electoral campaigns. Without giving up highlighting her motherhood, and the obvious fact that she is a woman, Manuela, when talking about issues related to the female universe, does not do it stereotypically showing a critical view on delicate topics, such as representativeness, the labor market, work, and violence.
\end{abstract}

Keywords: election campaign; social networks; essentialization; Manvela D'Ávila; Facebook

\footnotetext{
${ }^{1}$ Graduada em Ciências Sociais pela Universidade Federal de Viçosa e Mestranda em Ciências Sociais pela Universidade Federal de Juiz de Fora. E-mail: marques.gaabrielle@gmail.com
} 
Eleições e redes sociais: Uma análise das postagens da candidata Manuela...

\section{Introdução}

Mulheres uni-vos!

(Postagem realizada na página pessoal do Facebook de

Manuela D'Ávila em 17/09/2018)

A inserção na vida política é uma pauta do movimento feminista desde sua gênese. Conforme a historiografia clássica do movimento, sua primeira onda é caracterizada pela busca à igualdade jurídica, baseada no sufrágio universal e amplo acesso ao mercado de trabalho, bem como à educação. Após muitas lutas, as barreiras formais que separavam as mulheres da vida pública ruíram.

No Brasil o direito ao voto foi conquistado em 1932, mas, mesmo antes da conquista do sufrágio feminino, Alzira Soriano foi a primeira mulher a ser eleita a um cargo do executivo, em 1929 assumiu a prefeitura de Lajes, no Rio de Grande do Norte, sendo a primeira mulher prefeita da América Latina.

Já na primeira eleição após o processo de redemocratização, em 1989, havia uma única candidata mulher, Lívia Maria Pio pelo Partido Nacionalista (PN). Com apenas 30 segundos no Horário Gratuito de Propaganda Eleitoral (HGPE) a candidata falava diretamente com o público feminino "mulheres somos a maioria, venham comigo governar o Brasil"2, apontava as fallhas na política feita por homens e afirmava que as mulheres têm um jeito diferente de fazer política. (LIMA E PABKE, 2017).

O HGPE é uma importante fonte comunicacional dos partidos e candidatos com o eleitorado, devido sua obrigatoriedade e regulação própria representa um espaço livre das mediações exercidas pela mídia tradicional. Albuquerque e Tavares (2018) apontam como a campanha eleitoral de 1989 foi um momento decisivo para as pesquisas em Comunicação e Política no Brasil, destacando a importância dos técnicos em marketing político e de como o modelo brasileiro de propaganda política obtinha uma linguagem específica, tendo em vista a tendência de americanização das campanhas eleitorais.

o modelo brasileiro de propaganda política na televisão desenvolveu uma linguagem muito particular, derivada da necessidade de adaptar o conteúdo a ser exibido a uma quantidade de tempo prédeterminada, diferente para cada partido, definida pela legislação

2 Disponível em: https://www.youtube.com/watch?v=rWlaXYAvMP0,Acessado em 03/06/2019. 
Eleições e redes sociais: Uma análise das postagens da candidata Manuela...

eleitoral, bem como do fato de que propagandas de diferentes candidatos competirem pela atenção dos espectadores em um mesmo espaço, situado à parte da programação normal da televisão (ALBUQUERQUE, 1999 in ALBUQUERQUE E TAVARES, 2018, p. 152-153).

Acresce que os meios de comunicação não estão apartados da sociedade, de forma que carregam consigo símbolos, estereótipos e lógicas do cotidiano, o que também recai na construção da propaganda política. É o caso dos estereótipos de gênero, presente em diversas campanhas de candidatas mulheres, em todos os níveis de disputa eleitoral, como é o exemplo da campanha da Lívia Maria Pio.

Além disso, contemporaneamente vivenciamos o sucesso das redes sociais digitais, idealizadas como plataformas de encontro de pessoas, onde os internautas podem compartilhar e comentar diversos conteúdos, como imagens, vídeos e textos. Seus usos ultrapassaram o que fora imaginado, e atualmente as redes sociais possuem assumem diversas funções, inclusive, de plataforma política de candidatos e eleitos.

Essa nova forma de comunicação entre candidatos, partidos e eleitores levanta uma série de questionamentos: qual o espaço do HGPE, diante de outras plataformas de comunicação? Como são construídos os conteúdos divulgados pelos atores políticos? Como políticos se expõem nas redes sociais?, entre outras.

Dessa forma, o objetivo deste artigo é analisar como a candidata à vice-presidência no último pleito eleitoral (2018) Manuela D'Ávila (PT/PCdoB/PROS) utiliza de estereótipos de gênero como estratégia de campanha eleitoral no Facebook, além de outras estratégias que são utilizadas na rede. A escolha pela candidata se deve ao fato do seu uso intenso das redes socais e de como a mesma, durante sua trajetória política, sempre reforçou que era mãe, casando sua vida política com a maternidade, além de ser a candidata feminina com maior relevância no último pleito. Já a escolha pelo Facebook se deu pelo fato de que segundo a Pesquisa Brasileira de Mídia de 2015 (PBM, 2014) o Facebook é a rede mais utilizada pelos brasileiros (83\%).

O artigo se divide em cinco partes, cuja primeira busca traçar como uma parte da literatura vê a relação entre o HGPE e as redes sociais digitais, seguida por um debate mais profundo sobre como o gênero é mobilizado pelo marketing político. Após, são apresentadas a metodologia e a análise dos dados, bem como as considerações finais. 
Eleições e redes sociais: Uma análise das postagens da candidata Manuela...

\section{Do HGPE às redes sociais}

Os meios de comunicação são centrais na vida social, assim como na prática política. Miguel e Biroli (2010) constatam como a relação entre mídia e política despertam alterações e permanências em quatro eixos fundamentais: a mídia se coloca como instrumento na relação entre políticos e cidadãos, transforma os discursos políticos, interfere na produção da agenda pública e altera a gestão da visibilidade dos políticos.

"A visibilidade que a política de massas demanda coloca os meios de comunicação no centro da dinâmica política" (Miguel e Biroli, 2011, p. 2), de forma que não podem ser ignoradas pelos atores políticos, seja na construção de suas carreiras, seja na definição da agenda.

Isso fica ainda mais claro se nos debruçarmos sobre as campanhas eleitorais. A televisão representa um aspecto central nas campanhas políticas brasileiras, o Horário Gratuito de Propaganda Eleitoral (HGPE) simboliza um importante canal de comunicação entre os candidatos, partidos e o público, além de ser o principal meio de comunicação com o eleitorado.

O HGPE oferece para os partidos, candidatos e suas respectivas equipes de campanha, uma oportunidade de se apresentarem diretamente aos eleitores, independentemente da mediação exercida pelas organizações midiáticas tradicionais. Ele compõe o ambiente informacional dos eleitores (CERVI, 2010), tornando-se uma importante fonte de informação principalmente para os indecisos (LOURENÇO, 2011 in ALBUQUERQUE E TAVARES, 2018, p. 147).

O advento da internet e mais contemporaneamente das redes sociais tem modificado essa relação. Gomes (2016) ao refletir sobre a relação entre política e internet, mais especificamente dentro do campo e-democracy, ou seja, de como a democracia é afetada pelas plataformas digitais, compreende que esta relação pode ter uma dimensão tanto social quanto institucional. A questão geral que se coloca é como os partidos utilizam a internet, principalmente as redes sociais?

[...] o facto observável é que, com a popularização da internet e dos media digitais, os diferentes atores políticos (dentre eles os partidos) mais e mais estão transferindo as suas atividades para plataformas digitais, institucionalizando progressivamente um espaço de interação entre os diferentes atores políticos que alguns analistas políticos qualificaram como "sistema político virtual" (NORRIS, 2001 in BRAGA ET. AL. 2017, p. 335). 
Albuquerque e Tavares (2018) demonstram três tendências de mudança que apontam para uma diminuição da importância da propaganda política na televisão como instrumento de campanha eleitoral: a perda da centralidade da televisão aberta como principal meio de comunicação, em relação à televisão paga e às mídias digitais; as transformações associadas a decisões políticas e judiciais (diminuição do tempo de campanha eleitoral e restrições ao financiamento) e o impacto do judiciário no processo de deslegitimação da vida política.

No entanto, é importante destacar que segundo a Pesquisa Nacional por Amostra de Domicílios Contínua (Pnad C) divulgada pelo Instituto Brasileiro de Geografia e Estatística (IBGE), em 2016, $64,7 \%$ da população brasileira declarou ter acesso à internet, em contrapartida, haviam 63,3 milhões de pessoas off-line.

O acesso à internet também é desigual em relação as regiões do país. As regiões Nordeste e Norte eram as únicas a apresentar taxas de indivíduos conectados inferiores à média brasileira, de $52,3 \%$ e $54,3 \%$, respectivamente. Ou seja, a perda de centralidade, da televisão, como canal de comunicação e informação, não ocorre de forma universal no país. Além do acesso desigual, a pesquisa também destaca os usos distintos que são feitos da internet, de forma que a televisão permanece como o principal canal de informação de grande parte dos brasileiros.

É inegável que há uma apropriação das redes sociais digitais por parte dos atores políticos, seja no período de campanha eleitoral, seja após a eleição, divulgando a agenda política, através de campanha permanente, além de possibilitar uma plataforma de prestação de contas.

Sobre o período de disputa eleitoral, a literatura sobre política e internet entende que campanhas feitas nas redes mobilizam estratégias tradicionais em combinação com estratégias específicas para o ambiente on-line. Massuchin e Tavares (2015) argumentam que grande parte das estratégias estão relacionadas a estabelecer uma proximidade com o eleitor, mobilização e engajamento, sob uma nova perspectiva.

Enquanto a televisão permite a um conjunto limitado de agentes transmitir conteúdos para um número imenso de espectadores passivos, as mídias sociais implicam um tipo de atitude totalmente diferente: para que as mensagens possam seguir adiante e atingir um grande número de pessoas, é preciso contar com a colaboração ativa de um grande número de usuários. Nessas circunstâncias, os modelos consagrados de atuação dos especialistas do marketing 
Eleições e redes sociais: Uma análise das postagens da candidata Manuela...

político - a produção de material cuidadosamente embalado para - consumo dos telespectadores - não parece suficiente (ALBUQUERQUE E TAVARES, 2018, p. 167).

Além disso, os autores apontam que esse fenômeno já pode ser observado nas eleições para o executivo nacional de 2014, ao constatarem que diversos programas do HGPE indicavam as páginas on-line dos candidatos, e que o redirecionamento às páginas foi usado como estratégia por candidatos que dispunham de pouco tempo na televisão, como Eduardo Jorge (PV).

Braga et. al. (2017) demonstram que em setembro de 2015 todos os partidos utilizavam sites e redes sociais próprias: Facebook $(93,0 \%)$, Twitter $(96,8 \%)$ e canais específicos no YouTube $(96,0 \%)$ além de possuírem contas ativas no Instagram.

Além do mais, Sampaio, Bragatto e Nicolás (2016) constatam, a partir de uma pesquisa bibliométrica realizada com os artigos apresentados nos principais eventos das áreas de Sociologia, Ciência Política e Comunicação, entre 2000 a 2014, uma proximidade de estudos entre "redes sociais", "estratégia política" e "eleitoral e campanhas", o que pode significar, para os autores, o início de uma tendência de estudos mais próximos aos apresentados em Comunicação e Política (SAMPAIO ET. AL., 2016).

Assim, esta pesquisa busca lançar luz sobre esta lacuna, dentro dos limites possíveis, ao tentar compreender como são elaboradas as estratégias das campanhas de candidatas mulheres nas redes sociais digitais, observando deslocamentos e permanências em relação aos meios de comunicação tradicionais, tendo o gênero como categoria central de análise.

\section{As estratégias de mulheres candidatas}

É possível encontrar na literatura do campo da Ciência Política uma vasta herança que estuda a relação entre política e comunicação e uma menor que se debruça na relação entre gênero e política. Mas a interface entre os três campos, - comunicação, gênero, política - ainda é pouco desenvolvida (MIGUEL E BIROLI, 2011; MENDONÇA E OGANDO, 2013).

Sarmento (2013) aponta que a análise da forma com que os meios de comunicação representam as mulheres na mídia é extremamente relevante, já que são importantes na construção do capital político feminino, seja a partir dos veículos jornalísticos ou propagandas partidárias. Além disso, como demonstram Mendonça e Ogando (2013), devido à baixa representação de 
Eleições e redes sociais: Uma análise das postagens da candidata Manuela...

mulheres na política institucional os estudos sobre as relações entre gênero e política nas estratégias eleitorais são ainda pouco realizados.

\begin{abstract}
Mesmo que algumas mulheres tenham ocupado lugar central na política brasileira, não se notam muitos estudos sistemáticos sobre a forma como elas mobilizaram a questão 'do feminino' em suas campanhas (Mendonça e Ogando, 2013 p. 196).
\end{abstract}

Como apontam Miguel e Biroli (2011) e Biroli (2011), em um estudo seminal sobre esta área, existe na mídia um reforço de estereótipos femininos, como a ideia de maternidade ligada necessariamente às mulheres. Ainda que estes não sejam originários na mídia "sua permanência no discurso midiático pode colaborar para seu impacto e permanência" e "as formas de definir - e restringir - o papel da mulher nesse âmbito impõem limites às suas possibilidades de atuação em outras áreas, como a profissional e a política" (BIROLI, 2011, p. 128-129).

Nesse sentido, Biroli (2011), demonstra como os meios de comunicação representam sistematicamente as mulheres de forma estereotipada e as consequências disto, identificando deslocamentos e permanências nestas representações, tendo em vista que os estereótipos se modificam ao longo do tempo.

Nos meios de comunicação, os estereótipos de gêneros são mobilizados juntamente com a oposição entre o público e o privado. As diferenças no tratamento dada pela mídia às mulheres [...], assim como as diferenças entre essas mulheres - entre suas trajetórias e estratégias para a construção da imagem pública, entre suas posições em relação ao feminismo ou outras temáticas políticas - são variações que, na cobertura noticiosa analisada, não rompem com um fundo comum: o da definição do feminino a partir das relações domésticas, familiares e afetivas (BIROLI, 2011, p. 141).

No entanto, a representação estereotipada de mulheres não é feita somente a partir dos meios de comunicação, pesquisas (MENDONÇA E OGANDO, 2013; PANKE e IASULAITIS, 2016; LIMA e PANKE, 2017) apontam como candidatas a cargos políticos utilizam destes estereótipos enquanto recurso de marketing eleitoral.

Embora os estereótipos de gênero contaminem eleitores, candidatos e a cobertura da imprensa, eles nem sempre são handicaps, mas podem ser tomados pelas candidatas como vantagens em função da agenda de uma determinada eleição, em que são privilegiadas 
Eleições e redes sociais: Uma análise das postagens da candidata Manuela...

as áreas de conhecimento usualmente associadas às mulheres (Kahn, 1996). Ou ainda, quando associados a outras características das candidatas, como serem herdeiras legítimas de grupos familiares e de lideranças masculinas, apresentando-se como continuadoras das obras de seus pais, maridos ou padrinhos políticos (LITHGOW, 2000 in PANKE e IASULAITIS, 2016, p. 393).

Dessa forma, as campanhas de candidatas mulheres devem ser pensadas a fim de solucionar o que Panke e lasulaitis (2016) denominam de double bind, um dilema entre demonstrar o que são entendidas enquanto características femininas, cuidadosa, dócil, equilibrada, atenciosa, e características necessárias ao papel de liderança, que estaria no universo masculino, força, inteligência, pensamento estratégico. Ou seja, as candidatas precisam apresentar uma força assertiva mas sem parecerem masculinas.

Além disso, compreendendo que o ambiente on-line não representa um mundo à parte da sociedade, mas sim uma continuação, e consequentemente as estratégias utilizadas nas campanhas on-line não rompe, necessariamente, com as lógicas das estratégias tradicionais é interessante compreender se este fenômeno da essencialização da mulher enquanto maternal e cuidadora permanece nas campanhas realizadas nas redes online.

É importante ressaltar que a intenção não é analisar a eficácia dessas estratégias, mas conhecer como se dá a relação entre carreira política e um ideal de feminilidade que perpassa pela ideia da maternidade. Tendo em vista que a internet tem uma potencialidade para a circulação de novos discursos, cabe perguntar se ela possibilita um debate mais profundo sobre essa relação, que não tem espaço dentro do HGPE.

\section{Metodologia}

A metodologia utilizada foi a análise de conteúdo das postagens que estão disponíveis na página do Facebook da Manuela D'Ávila. Foram utilizadas uma dimensão quantitativa e qualitativa. A dimensão quantitativa busca apresentar uma análise descritiva do banco de dados de formal geral. Já a dimensão qualitativa possibilita compreender de forma mais acentuada o conteúdo das postagens realizadas pelo perfil da então candidata.

A coleta das postagens se deu através do Netvizz, um aplicativo disponível no site da própria rede social, que permite a mineração dos posts na plataforma, fomentando o banco de dados. O período de coleta seguiu o estipulado pelo Tribunal Superior Eleitoral (TSE) 
Eleições e redes sociais: Uma análise das postagens da candidata Manuela...

para o HGPE, entre 31 de agosto e 4 de outubro de 2018, respectivo ao primeiro turno e entre 12 a 26 de outubro de 2018, período definido para o segundo turno, totalizando 49 dias, a fim de realizar um recorrente no momento em que a campanha política é mais intensa.

Importante salientar que as postagens selecionadas foram feitas exclusivamente pela página oficial da candidata, excluindo postagens feitas por terceiros e compartilhadas na página. As postagens foram organizadas no banco de dados conforme categorias estabelecidas pela literatura que estuda o fenômeno da campanha política nas redes (MASSUCHIN e TAVARES, 2015), acrescida da categoria mulher, destacando quando um post tratava especificamente de questões ligadas a esse grupo, bem como, outras que se mostraram pertinentes e serão explicitadas a seguir.

Além disso, questões como o tipo de postagem (foto, texto ou vídeo), se o vídeo era gravado ou se era uma transmissão ao vivo, também representam variáveis do banco. A quantidade de comentários, curtidas, reações e compartilhamentos também estão presentes no banco, mas não serviram de objeto de análise, tendo em vista o objetivo da pesquisa.

Para Massuchin e Tavares (2015) as campanhas políticas realizadas nas redes sociais tendem a aglutinar estratégias tradicionais com estratégias específicas para as redes sociais, a fim de forjar uma proximidade com o eleitor, mobilizando e engajando-o. Com isso, estabelecem cinco categorias que possibilitam a análise das estratégias.

1) Disseminação de informação: Refere-se à divulgação de informação política necessária a decisão do voto. $O$ conteúdo pode ser mais temático ou mais voltado para a campanha em si do candidato, como a divulgação da agenda.

2) Proposição de temas/políticas. Divulgação do plano de governo, popularização das propostas e discussão de problemas políticos.

3) Campanha negativa: Ressaltar as características negativas dos adversários.

4) Engajamento e mobilização: Envolver os cidadãos na campanha e encorajar outros participantes, tanto online quanto off-line. Convidando para manifestações nas ruas e compartilhamento de hashtags.

5) Interação com eleitores. Estabelecer um diálogo com os eleitores de forma mais direta. 
Eleições e redes sociais: Uma análise das postagens da candidata Manuela...

Porém, durante a observação dos dados outras categorias pareceram relevantes e foram acrescidas a estas, são elas:

6) Mulher: Tendo em vista o objetivo do trabalho, de conhecer a mobilização de estereótipos de gênero enquanto estratégia de campanha política, fez-se necessário isolar as postagens que tratavam especificamente de pautas ligadas a mulheres.

7) EleNão: Organizado no próprio Facebook, a partir de um grupo denominado Mulheres Unidas Contra o Bolsonaro, o EleNão foi um movimento social contemporâneo (SOUSA e RACHIT, 2019). A opção por isolá-lo das outras categorias se deve ao fato de ser um movimento maior do que a campanha da candidata, foi uma mobilização de mulheres contra a candidatura de Bolsonaro. $O$ uso da \#EleNão era feito em postagens de protesto, e que objetivavam a derrota do candidato nas urnas. No dia 29 de setembro de 2018 em diversas cidades do Brasil ocorreram manifestações organizadas a partir dos grupos do Facebook.

8) Combate à fake news. Apesar da divulgação de notícias falsas não ser um acontecimento inédito do último pleito o que se observou foi a intensificação desse fenômeno. Dessa forma, foi possível observar nas postagens da página de Manuela uma tentativa de combater as informações falsas que eram divulgadas sobre ela, seu partido e o candidato à presidência Fernando Haddad.

Após a coleta e categorização dos dados, um segundo banco foi criado, isolando as postagens enquadradas na categoria mulher, a fim de analisar de forma mais profunda o seu conteúdo. A apresentação da análise dos dados e possíveis considerações será feita no tópico a seguir.

\section{A campanha de Manuela D'Ávila no Facebook}

Manuela Pinto Vieira d'Ávila (Porto Alegre, 18 de agosto de 1981) é uma jornalista e política brasileira. Filiada ao Partido Comunista do Brasil (PCdoB), foi deputada federal pelo Rio Grande do Sul entre 2007 a 2015, sendo a deputada mais votada em 2010, já entre 2015 e 2019 ocupou o cargo de deputada estadual e em 2018 foi candidata a vice-presidente da República junto a Fernando Haddad pela coligação entre Partido dos Trabalhadores (PT), PCdoB e Partido Republicano da Ordem Social (PROS).

Sua trajetória política iniciou-se no movimento estudantil em 1999 e no mesmo ano filiou-se à União da Juventude Socialista (UJS). De 
Eleições e redes sociais: Uma análise das postagens da candidata Manuela...

2001 a 2003 integrou a direção nacional da UJS e a vicepresidência da União Nacional dos Estudantes (UNE).

Segundo seu próprio site ${ }^{3}$ Manuela é um "fenômeno das redes sociais" que utiliza a "internet como instrumento de transparência". Assman e Pozobon (2012) em uma pesquisa sobre a utilização de redes sociais pela então deputada, constataram que em 2012, Manuela possuía 14 contas ativas em diferentes redes sociais, além de um blog pessoal.

Outro aspecto relevante de sua trajetória política, que também é ressaltado em seu site pessoal, é o nascimento de sua filha Laura.

Após ser mãe, [Manuela] começa a aprofundar-se na militância
sobre as questões relacionadas à figura materna ao mesmo tempo
em que levanta a bandeira feminista. Pode-se notar nas suas mídias
sociais digitais a presença de elementos que a identificam como
mãe, política e feminista assimilando cada vez mais sua presença
nessas esferas (PONS E FOLETTO, 2017, p. 6).

A última eleição para presidente (2018) foi marcada pelo uso intenso das redes sociais digitais por diversos candidatos. Twitter, Instagram, Facebook e WhatsApp foram mobilizados como plataformas de campanha de candidatos tanto à esquerda quanto à direita. Com funcionalidades diferentes, cada rede requer um conjunto de estratégias comunicacionais distintas, além de alcançar públicos diferentes. Lançado em 2004, o Facebook é a rede social mais utilizada pelos brasileiros (PBM, 2014).

O Facebook permite a criação de um perfil, onde o usuário pode alimentá-lo com as informações que deseja. Uma vez conectado à rede social, é possível encontrar amigos, páginas dos mais diversos conteúdos, participar de grupos (fóruns online sobre um tema específico), enviar e receber mensagens de forma privada ou pública.

A página da então candidata possui $1.403 .998^{4}$ seguidores e está no ar desde agosto de 2010. Suas postagens abordam inúmeros temas, pautas que estão no debate público com mais intensidade, posicionamento político, divulgação de acontecimentos de sua vida pessoal, bem como o compartilhamento de memes. Manuela também utiliza dos vários recursos que a plataforma disponibiliza para além da postagem de texto, como a exposição de imagens, vídeos gravados previamente e ao vivo (lives).

Disponível em: http://www.manuela.org.br/?page id=2

Dado coletado em 07/08/2019

CSOnline - Revista Eletrônica de Ciências Sociais - nº 31 (2020). 
Eleições e redes sociais: Uma análise das postagens da candidata Manuela...

As principais estratégias utilizadas pela deputada Manuela nos ambientes digitais, buscam aproximar-se dos seus eleitores, em sua maioria jovem, bem como, produzir e legitimar suas principais temáticas de luta, como a questão de gênero" (PONS E FOLETTO, 2017, p. 3).

Durante o período recortado para a coleta dos dados Manuela e sua equipe fizeram 181 postagens. Desse total, 116 postagens foram realizadas no primeiro turno $(64,09 \%)$ e 65 foram feitas já no segundo turno $(35,91 \%)$.

Em relação ao tipo de conteúdo divulgado nas postagens é interessante notar, conforme atesta a Tabela 1 , que há uma predominância do uso de vídeos como recurso, em relação a divulgação de imagens. De maneira geral, as postagens apresentam textos curtos convidando o leitor a assistir o vídeo que acompanha.

Tabela 1: Tipos de posts

\begin{tabular}{|l|r|r|}
\hline Tipo de Post & Total & $\%$ \\
\hline Foto & 7 & $3,87 \%$ \\
\hline Vídeo & 174 & $96,13 \%$ \\
\hline Total Geral & 181 & $100 \%$ \\
\hline
\end{tabular}

Fonte: Dados da pesquisa

A Tabela 2 demonstra a relação entre vídeos gravados previamente a as transmissões ao vivo. $O$ uso de lives pode ser considerado uma novidade do último pleito, tendo em vista que era um recurso recente disponibilizado pelo Facebook. As transmissões ao vivo são realizadas tanto em eventos, como caminhadas e comícios, quanto em momentos em que a candidata conversa com os eleitores sobre os acontecimentos da disputa eleitoral.

Tabela 2: Uso de live

\begin{tabular}{|l|r|r|}
\hline Live & Total & $\%$ \\
\hline Não & 132 & 72,93 \\
\hline Sim & 49 & 27,07 \\
\hline
\end{tabular}

CSOnline - Revista Eletrônica de Ciências Sociais - nº 31 (2020). 
Eleições e redes sociais: Uma análise das postagens da candidata Manuela...

\begin{tabular}{|l|r|r|}
\hline Total & 181 & 100 \\
\hline
\end{tabular}

Fonte: Dados da pesquisa.

No que diz respeito aos diferentes tipos de estratégias utilizados, é possível perceber uma predominância da disseminação de informação (46,41\%): são divulgados resultados de pesquisas de intenção de votos, a agenda da candidata, participação em eventos, depoimentos de endosso de pessoas famosas.

Tabela 3: Distribuição das categorias

\begin{tabular}{|l|r|r|}
\hline Categorias & Total & $\%$ \\
\hline Campanha Negativa & 9 & 4,97 \\
\hline Combate à Fake News & 6 & 3,31 \\
\hline $\begin{array}{l}\text { Disseminação de } \\
\text { Informações }\end{array}$ & 84 & 46,41 \\
\hline \#EleNão & 11 & 6,08 \\
\hline $\begin{array}{l}\text { Engajamento e } \\
\text { Mobilização }\end{array}$ & 37 & 20,44 \\
\hline $\begin{array}{l}\text { Interação com os } \\
\text { Eleitores }\end{array}$ & 1 & 0,55 \\
\hline
\end{tabular}


Eleições e redes sociais: Uma análise das postagens da candidata Manuela...

\begin{tabular}{|l|r|r|}
\hline Mulheres & 16 & 8,84 \\
\hline $\begin{array}{l}\text { Proposição de } \\
\text { temas/políticas }\end{array}$ & 17 & 9,39 \\
\hline Total Geral & 181 & 100 \\
\hline
\end{tabular}

Fonte: Dados da pesquisa.

É interessante ressaltar que, apesar da hipótese de a internet possibilitar o diálogo de forma mais direta com o eleitor, apenas uma postagem de todo o universo da pesquisa se enquadra nessa categoria, interação com eleitores. Nela, a candidata brinca com um jargão popular nas redes, o \#sextou. "E ai galera falta pouco para sair aquele famoso grito de \#sextou por ai?" (Postagem feita no dia 14/09/2018 às 19:20).

Seguida da estratégia de disseminação de informação, a estratégia de engajamento e mobilização, é a segunda mais utilizada. Aqui, é importante destacar o uso das hashtags, uma constante nas postagens analisadas, e que também representa uma característica do último pleito.

Gráfico 1: Distribuição das categorias

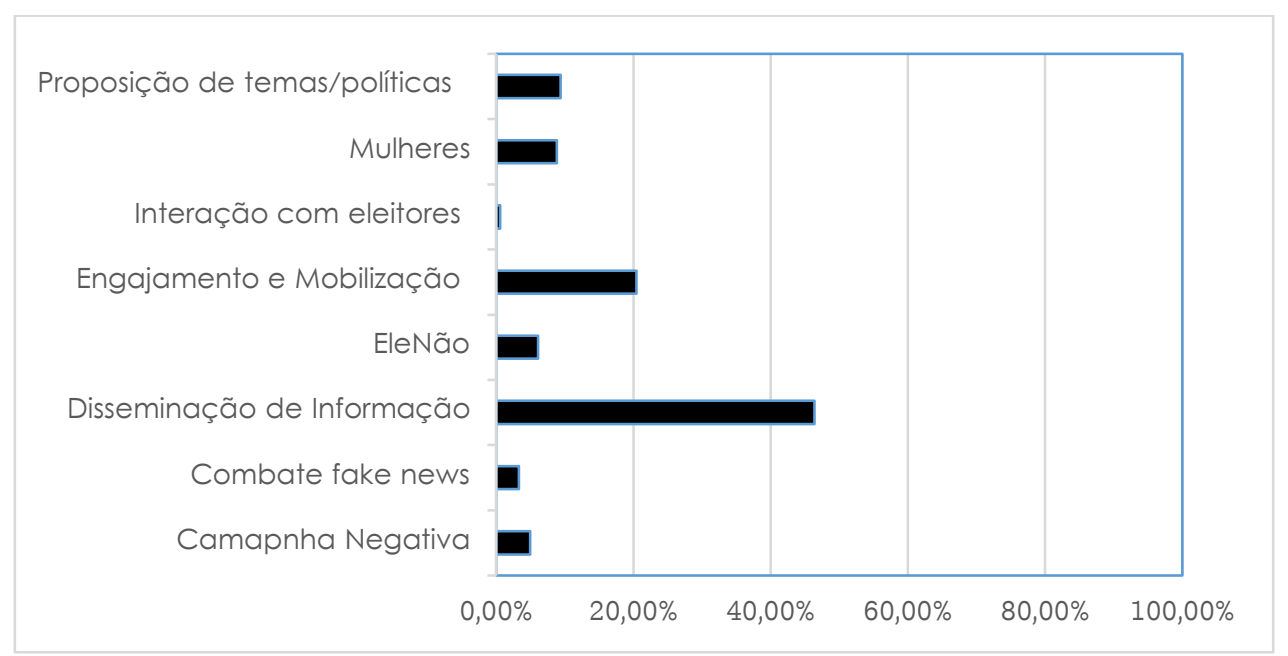

Fonte: Dados da pesquisa. 
Eleições e redes sociais: Uma análise das postagens da candidata Manuela...

A hashtag é formada por uma palavra ou frase iniciada pelo símbolo \#, funciona como uma etiqueta on-line que indexa todos os posts que são marcados com ela. Isso facilita 0 compartilhamento em larga escala, e por isso passou a ser um recurso utilizado por diversas manifestações. O princípio do uso político das hastags é identificado com a onda de protestos ocorridas em alguns países árabes no ano de 2010 (COSTA-MOURA, 2014).

\begin{abstract}
Mas o que implica esse elemento novo do discurso que não cabe no registro da reivindicação, nem da palavra de ordem, e configura um domínio próprio, outro: o streamimg incessante das \#hastags? Protestos iniciados na rede e inteiramente articulados através das novas tecnologias de comunicação evidenciam, a cada dia, que estas tecnologias não são apenas ferramentas de descrição do mundo. Elas são formas novas de criação e desconstrução da realidade. Quando alguém atua por meio dessas chamadas "redes sociais" não está simplesmente real - alterando, de forma inédita, o ativismo político e social e os modos de participação no discurso (COSTA-MURA, 2014, p.146)
\end{abstract}

Dessa forma, a campanha on-line de Manuela D'Ávila utiliza tanto de hashtags criadas para esse fim, quanto a apropriação de outras hashtags que já circulavam nas redes. São exemplos, \#ManunoJaburu, \#ViraVoto, \#vote13, \#OBrasilFelizDeNovo. As hashtags aparecem sempre finalizando o texto e representam uma forma de engajar os eleitores, principalmente através do compartilhamento.

Outro aspecto relevante é a baixa predominância de postagens que visam propor temas e políticas, estratégia ligada a compartilhar o plano de governo do candidato. Apenas 17 postagens $(9,39 \%)$ se enquadravam nesta categoria, e mesmo dentro da categoria, poucas falavam de pautas ligadas ao plano de governo em si, a maioria abordava a discussão de problemas políticos que estavam em pauta no momento, como o estatuto do desarmamento, memórias da ditadura, direito de minorias.

Também é possível constatar um esforço por parte da candidata em combater notícias falsas que foram divulgadas sobre ela e seu partido. Em seis postagens (3,31\%) Manuela D'Ávila desmente de forma direta fake news.

Bolsonaro além de covarde, defensor da tortura, é um mentiroso!!! Ele usou um vídeo distorcido montado em seu programa de TV para nos atacar. Vejam o vídeo real! Espalhem a verdade! 
Eleições e redes sociais: Uma análise das postagens da candidata Manuela...

\#HaddadPresidente \#ManuNoJaburu. (Postagem feita no dia 26/10/2018 às 01:52)

Do universo da pesquisa, entre 181 postagens, 16 (8,84\%) falavam diretamente sobre pautas ligadas às mulheres ou com o público feminino. Os temas que aparecem são sobre mercado de trabalho, violência, representatividade feminina na política, e postagens mais gerais, que não tratam de uma pauta específica do movimento feminista mas fala diretamente com o público feminino. Aqui, a presença de hashtags nas postagens também chama a atenção. Sobre as mulheres, as hashtags mobilizadas foram \#mulheresnapolítica \#lutecomoumagarota e \#elenão.

No que tange ao mercado de trabalho, além de o tema aparecer como pauta do público feminino, (mais vagas para mulheres poderem trabalhar), Manuela também fala sobre a necessidade de creches, compreendendo que esta é uma relação intrínseca, devido à responsabilização, quase exclusiva, por parte das mulheres, pelo cuidado das casas e dos filhos. Para ingressar no mercado de trabalho, além de vagas disponíveis, é necessário que exista um ambiente seguro para deixar as crianças.

Nós falamos que queremos que a mulher possa entrar e permanecer
no mercado de trabalho e Haddad quando prefeito criou 100 mil
vagas em creches em São Paulo. Essa é a vida real. \#ManuNoUol
\#UolNasUrnas \#ManuNoJaburu (Postagem feita no dia 02/10/2018 às
18:30).

Os temas da violência e da maternidade são mencionados de maneira mais superficial. Ambos são tematizados em resposta a comentários feito pelo candidato da oposição Jair Messias Bolsonaro (PSL). A disputa eleitoral de 2018 foi marcada por um intenso confronto entres os candidatos da chapa de Manuela e da oposição, divergindo sobre pautas econômicas e de justiça social. Em um evento na cidade de São Paulo, o candidato à vicepresidência, ao lado de Bolsonaro, General Mourão, falou que famílias pobres compostas apenas pela mãe e a avó são "fábricas de desajustados". Manuela se posicionou contra tal afirmação em sua rede social.

Existe como uma mulher que é mãe e que cria o filho sozinha votar em alguém que diz que uma mulher que faz o sacrifício de criar um filho sozinha cria um desajustado? \#EleNÃO \#ManuNoJaburu (Postagem feita no dia 29/08/ 2018 às 13:18). 
Eleições e redes sociais: Uma análise das postagens da candidata Manuela...

Além disso, se destaca o uso da ideia de representatividade de mulheres na política como estratégia de campanha. Grande parte das postagens se dedica a demonstrar como uma política justa precisa que mulheres estejam sendo representadas de forma coerente.

\begin{abstract}
Nós somos o time das mulheres brasileiras porque nós temos um projeto de país que liberta ao povo brasileiro. E não existe liberdade ao povo brasileiro sem garantir liberdade para as mulheres. Manuela D'Ávila candidata a vice-presidenta de Fernando Haddad e Lula na \#PrimaveraDasMulheres em São Paulo. \#HaddadPresidente \#ManuNoJaburu (Postagem feita no dia 27/09/2018 às 15:25).
\end{abstract}

Ainda que a representatividade feminina seja um dos temas mais abordados pela candidata, Manuela entende que 0 fato de elegermos mais mulheres não faz uma correlação direta com uma política que apoia as pautas dos movimentos feministas. $O$ post a seguir é um exemplo disso: "É preciso eleger mais mulheres para garantir representatividade democrática, mas, acima de tudo, mulheres comprometidas com a emancipação feminina \#MulheresNaPolítca \#ManuNoJaburu" (Postagem feita no dia 28/08/2018 às 15:08).

Manuela D'Ávila também aproveita sua página no Facebook para destacar sua trajetória como uma mulher política e mãe. Em mais de uma postagem a candidata divulga dados sobre sua vida pessoal e política, ressaltando que a atividade política também é realizada por mulheres, e no seu caso, uma mulher jovem.

Hoje é aniversário da União da Juventude Socialista UJS. Nesse 2018 completam-se 20 anos do dia em que eu estava em sala de aula e uma outra menina, a Letícia, se aproximou com um xerox de uma ficha de filiação à UJS e eu fiz uma opção, como uma garota, de lutar por coisas que são as mais importantes. \#LuteComoUmaGarota (Postagem feita no dia 22/08/2018 às 13:39).

Em suma, a página no Facebook de Manuela D'Ávila mobiliza diversas estratégias de marketing político on-line, além de apresentar, mesmo que em uma pequena quantidade, preocupações com as pautas dos movimentos feministas. Algumas considerações sobre os dados obtidos pela análise serão feitas a seguir.

\title{
Considerações Finais
}


Eleições e redes sociais: Uma análise das postagens da candidata Manuela...

Nos momentos de disputa eleitoral, os candidatos e partidos se veem em uma intensa competição por eleitores, sendo um momento crucial à democracia. O HGPE foi por muito tempo o meio de comunicação central neste jogo, mas sua centralidade tem sido questionada a partir da emergência das redes sociais digitais.

Em consonância com Massuchin e Tavares (2015), fica evidente a partir da análise dos dados que, ao contrário do que os primeiros estudos sobre campanhas eleitorais on-line defendiam, o uso da internet serve mais do que para apenas informar a agenda dos candidatos. As análises evidenciam como uma série de estratégias são mobilizadas e como novas surgem com o tempo, conforme novos recursos também são disponibilizados pelas plataformas.

Dentro das estratégias tradicionais das campanhas, muitas vezes os estereótipos de gênero são mobilizados como recurso para legitimar a candidatura de uma mulher, essencializando-a dentro de características que tendem a ser entendidas enquanto femininas.

O uso da página do Facebook de Manuela aponta para outras possibilidades. Sem abrir mão de destacar sua maternidade e o óbvio fato de que é uma mulher, Manuela quando fala sobre questões relacionadas ao universo feminino não o faz de forma essencializada. Demonstra uma visão crítica, sobre temas delicados, como representatividade.

Porém, apesar de se declarar feminista, foi possível perceber que as pautas ligadas aos movimentos feministas foram pouco presentes no período da campanha analisado. E que os temas que aparecem são os mais clássicos, como mercado de trabalho e violência. Questões de interseccionalidade entre raça, classe e sexualidade não são mencionadas.

\section{Referências Bibliográficas}

ALBUQUERQUE, Afonso de. Política versus televisão: o horário gratuito na campanha presidencial de 1994. Comunicação \& Política, v. 1, n. 3, p. 49-54, 1995.

ALBUQUERQUE, Afonso de; TAVARES, Camilla. Horário Gratuito de Propaganda Eleitoral: estilo, estratégias, alcance e os desafios para o futuro. In: FIGUEIREDO, Argelina Cheibub; BORBA, Felipe (org.). 25 anos de eleições presidenciais no Brasil. Curitiba: Appris, 2018. p. 147-169.

ASSMANN, Gabriela; DE OLIVEIRA POZOBON, Rejane. Os blogs como instrumentos de prestação de contas na esfera pública interconectada: o blog da deputada federal Manuela D'Ávila. Anagrama, v. 5, n. 2, p. 1-14, 2011. 
Eleições e redes sociais: Uma análise das postagens da candidata Manuela...

BIROLI, Flávia. Gênero e família em uma sociedade justa. Teoria Política e Feminismo: abordagens brasileiras. Vinhedo: Editora Horizonte, pág, p. 211-242.

BIROLI, Flávia. Mulheres e política na mídia brasileira: estereótipos de gênero e marginalidade do "feminino" na política. Mulheres, política e poder, p. 127, 2011.

FIGUEIREDO, Argelina Cheibub; BORBA, Felipe. 25 Anos de Eleições Presidenciais no Brasil. Editora Appris, 2019. Horário Gratuito de Propaganda Eleitoral: Estilo, Estratégias, Alcance e os Desafios para o Futuro

GILLIGAN, Carol. Imagens de relação. Teoria política feminista: textos centrais. Vinhedo, Ed. Horizonte, p. 81-119, 2013.

LIMA, Alice Marina Lira; PANKE, Luciana. DA PRIMEIRA CANDIDATA À PRIMEIRA ELEITA À PRESIDÊNCIA DO BRASIL: tipologias femininas no HGPE de TV de Lívia Maria e de Dilma Rousseff.

GOMES, Wilson. Anos de política, estado e democracia digitais: uma cartografia do campo. Democracia digital, comunicação política e redes: teoria e prática, p. 25-45, 20.

MATOS, Marlise. A sub-representação política das mulheres na chave de sua subteorização na ciência política. Mulheres, Poder e Política: a experiência do Brasil e do Canadá, v. 1, p. 22-54, 2012.

MATOS, Marlise. Teorias de gênero ou teorias e gênero? Se e como os estudos de gênero e feministas se transformaram em um campo novo para as ciências. Estudos Feministas, p. 333-357, 2008.

MENDONÇA, Ricardo F.; OGANDO, Ana C. Discursos sobre o feminino. Um mapeamento dos programas eleitorais de Dilma Rousseff. Revista Brasileira de Ciências Sociais, v. 28, n. 83, p. 195-216, 2013.

MENDONÇA, Ricardo Fabrino; GUIMARÃES SIMÕES, Paula. Enquadramento. Diferentes operacionalizações analíticas de um conceito. Revista Brasileira de Ciências Sociais, v. 27, n. 79, 2012.

MIGUEL, Luis Felipe. Desvelo e interesse na teoria feminista. Teoria política e feminismo: abordagens brasileiras. Vinhedo: Horizonte, p. 103-126, 2012.

MIGUEL, LUis Felipe; BIROLI, Flávia. Caleidoscópio convexo: mulheres, política e mídia. Editora Unesp, 2011.

MIGUEL, Luis Felipe; BIROLI, Flávia. Comunicação e política: um campo de estudos e seus desdobramentos no Brasil. Mídia, representação e democracia. São Paulo: HUCITEC, v. 1, p. 7-24, 2010.

MIGUEL, LUis Felipe; BIROLI, Flávia. Feminismo e política: uma introdução. São

MIGUEL, LUis Felipe; BIROLI, Flávia. Introdução: teoria política feminista, hoje. Teoria política feminista: textos centrais. Vinhedo, Ed. Horizonte, p. 7-54, 2013.

MASSUCHIN, Michele Goulart; TAVARES, Camilla Quesada. Campanha eleitoral nas redes sociais: estratégias empregadas pelos candidatos à Presidência em 2014 no Facebook. Compolítica, v. 5, n. 2, p. 75-112, 2015.

NORRIS, Pippa. Preaching to the converted? Pluralism, participation and party websites. Party politics, v. 9, n. 1, p. 21-45, 2003. 
Eleições e redes sociais: Uma análise das postagens da candidata Manuela...

PONS, Émilly; FOLETTO, Rafael. AS ESTRATÉGIAS DE COMUNICAÇÃO POLÍTICA DA DEPUTADA ESTADUAL MANUELA D'ÁVILA PARA A ARTICULAÇÃO DA IMAGEM DE MÃE E PARLAMENTAR. 2017.

PATEMAN, Carole. O contrato Sexual (1988). Tradução de Marta Avancini. São Paulo: Paz e Terra, 1993.

Paulo: Boitempo, 2014.

SARMENTO, Rayza. Das sufragistas às ativistas 2.0: feminismo, mídia e política no Brasil (1921 a 2016). Tese (Doutorado em Ciência Política) - Faculdade de Filosofia e Ciências Humanas, Universidade Federal de Minas Gerais, 2017.

SARMENTO, Rayza. Mídia, gênero e política: breve mapeamento de horizontes analíticos. Ação Midiática-Estudos em Comunicação, Sociedade e Cultura., v. 1, n. 5, 2013.

SOARES BRAGA, Sérgio; CAETANO ROCHA, Leonardo; CUNHA CARLOMAGNO, Márcio. Estratégias de comunicação digital dos partidos brasileiros e portugueses: um estudo comparado. Análise Social, n. 223, p. 328-359, 2017.

TAVARES, Camilla Quesada; MASSUCHIN, Michele Goulart. Comunicação, gênero e política no Brasil: As candidatas do Paraná na propaganda eleitoral televisiva.

Chasqui: Revista Latinoamericana de Comunicación, n. 135, p. 39-54, 2017. 